http://dx.doi.org/10.7494/drill.2017.34.3.701

\author{
Tomasz Włodek*
}

\title{
THE RETROGRADE CONDENSATION PROBLEM IN NATURAL GAS PIPELINE TRANSPORTATION SYSTEM**
}

\section{INTRODUCTION}

Natural gas prepared for pipeline transportation must have appropriate parameters described in norms and standards. This entails a restrictive approach to acceptable changes in natural gas composition in pipeline transmission systems. The greater number of entry points to a pipeline transmission system, the greater the probability of natural gas diversity in terms of the content of its individual components. It particularly concerns the natural gas sources in which treatment methods are not sufficiently accurate. It also concerns imported gas which may be of worse quality than that required by the standards. In specific cases when natural gas with a higher content of heavier hydrocarbons such as propane and butanes enters the transportation system, it is possible for the phenomenon of retrograde (reverse) condensation to occur. The occurrence of the twophase system significantly worsens the pipeline transport conditions, causing significant pressure drops in the transported natural gas. The article examines cases where the phenomenon of retrograde (reverse) condensation occurred in the pipeline transportation of natural gas $[1,2]$.

\section{RETROGRADE CONDENSATION}

The classic definition of retrograde condensation is used in reservoir engineering (especially engineering of condensate gas reservoirs) and in the process of the exploitation of condensate gas reservoirs (separation process). This definition describes the formation of liquid hydrocarbons in a gas reservoir as the pressure in the reservoir decreases

* AGH University of Science and Technology, Faculty of Drilling, Oil and Gas, Krakow, Poland

** This work was prepared within the framework of the statutory research of the Natural Gas Department, Faculty of Drilling, Oil and Gas, number: 11.11.190.555 
below dew point pressure during production. Some of the gas components condense into a liquid under isothermal conditions instead of expanding or vaporizing when pressure is decreased [2].

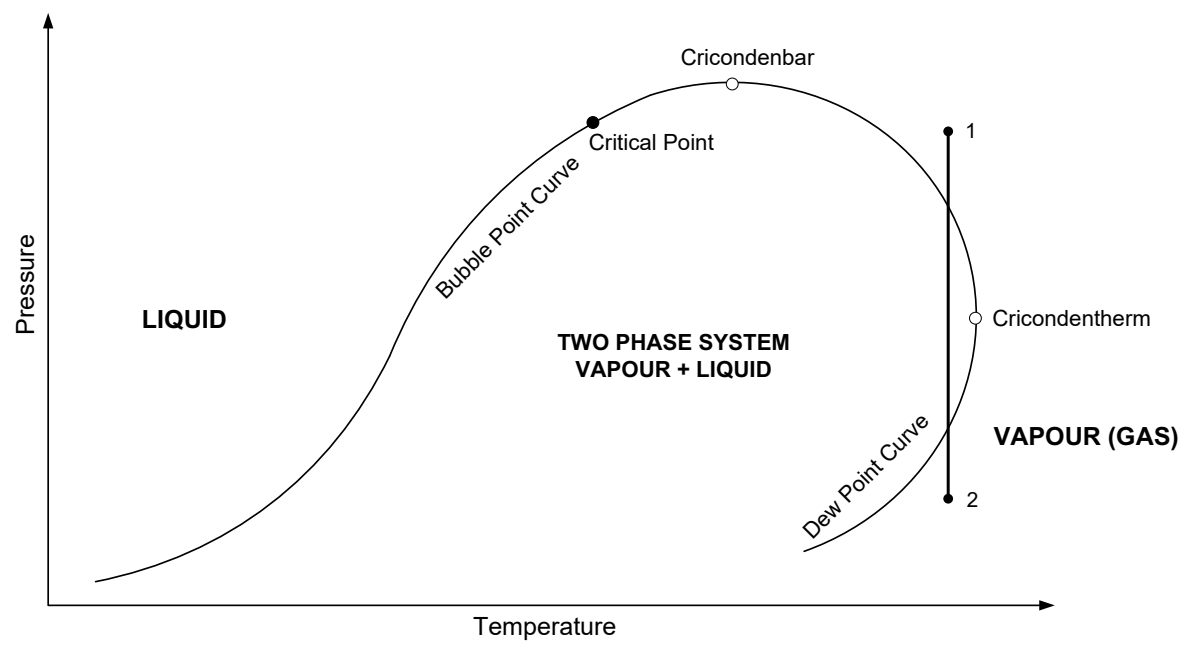

Fig. 1. Typical phase envelope chart (p-T plot) for condensate natural gas

The classic retrograde (reverse) condensation phenomenon is shown in Figure 1, where during the process of an isothermal pressure drop, the occurrence of a liquid phase in twophase system can be observed (process 1-2). In pipeline conditions, the process of natural gas temperature changes in many cases is close to isothermal conditions. The temperature of the transported natural gas is constant and generally close to the ambient temperature after several kilometres from the inlet point for dry gas. The occurrence of the two-phase system can affect temperature changes due to the high pressure drops and possible impact of the Joule-Thomson effect. The occurrence of a liquid phase in natural gas pipelines may also cause operational problems during the process of transport.

\section{MODEL ASSUMPTIONS}

The thermodynamic model of natural gas flow was based on a selected pipeline, the parameters of which are presented in Table 1. To increase the accuracy of calculations in the presented model, the numerical integration method of rectangles with midpoint rule was used. The pipeline will be buried at the depth of $1 \mathrm{~m}$ below ground level.

The compositions of selected natural gases used for calculations are presented in Table 2, whereas the $\mathrm{p}-\mathrm{T}$ phase envelopes for a given composition and range of temperatures -100 to $20^{\circ} \mathrm{C}$. Composition I contains heavier hydrocarbons and it is similar to typical condensate natural gas composition (except pentanes and hexanes). Composition II is chosen for comparative calculations, this composition is close to a typical dry gas with a dominant fraction of methane. 
Table 1

Basic parameters of the analyzed natural gas pipeline

\begin{tabular}{|l|c|c|}
\hline Inner diameter & $D$ & $300 \mathrm{~mm}$ \\
\hline Pipeline Length & $L$ & $200 \mathrm{~km}$ \\
\hline Thermal conductivity of pipeline steel & $k$ & $67 \mathrm{~W} / \mathrm{mK}$ \\
\hline Volume flow rate & $Q$ & $55000 \mathrm{Nm} / \mathrm{h}$ \\
\hline Inlet pressure & $p_{1}$ & $6 \mathrm{MPa}$ \\
\hline Inlet temperature & $T_{1}$ & $15^{\circ} \mathrm{C}$ \\
\hline Ambient temperature & $T_{\text {out }}$ & $5^{\circ} \mathrm{C}$ \\
\hline Burial depth & $x$ & $1 \mathrm{~m}$ \\
\hline Relative pipeline roughness & $\varepsilon$ & 0.000125 \\
\hline
\end{tabular}

Table 2

Exemplary compositions of condensate gas and dry gas

\begin{tabular}{|l|c|c|c|}
\cline { 3 - 4 } \multicolumn{2}{c|}{} & $\begin{array}{c}\text { Composition I } \\
\text { Condensate gas }\end{array}$ & $\begin{array}{c}\text { Composition II } \\
\text { Dry gas } \\
\text { (High methane) }\end{array}$ \\
\hline Component & Short symbol & Molar fraction [\%] & Molar fraction [\%] \\
\hline Methane & $\mathrm{C}_{1}$ & 83.0 & 93.0 \\
\hline Ethane & $\mathrm{C}_{2}$ & 7.0 & 4.0 \\
\hline Propane & $\mathrm{C}_{3}$ & 6.0 & 2.0 \\
\hline n-Butane & $\mathrm{nC}_{4}$ & 2.0 & 0.5 \\
\hline iso-Butane & $\mathrm{iC}_{4}$ & 2.0 & 0.5 \\
\hline
\end{tabular}

\section{PHASE EQUILIBRIA CALCULATIONS}

The basic parameter which describes phase equilibrium is dimensionless equilibrium ratio of mixture component $i$. It is described as the quotient of a molar fraction of component $i$ in vapour phase by molar fraction of this component in liquid phase [2]:

$$
K_{i}=\frac{y_{i}}{x_{i}}
$$

Complementing it with the Raoult-Dalton law, it can be written as:

$$
K_{i}(p, T)=\frac{p_{i}^{\text {sat }}}{p}=\frac{y_{i}}{x_{i}}
$$


The equilibrium ratio $\left(K_{i}\right)$ may also be calculated from a semi-empirical Wilson equation and used for the numerical solution of Rachford-Rice equation. Then, using an appropriate equation of state (e.g. Peng-Robinson EOS or its modifications), it is possible to determine the fugacity coefficients and compressibility factor for vapour and liquid phases. It is possible to calculate molar fractions of each phase in defined pressure and temperature conditions. Also as a result of these flash calculations we can obtain the compositions of liquid and vapour phases in these conditions. Other thermodynamic parameters of vapour and liquid phases may be calculated (i.e. compressibility factor, density, isobaric heat capacity). Modelling of the phase behaviour of hydrocarbon systems requires a suitable thermodynamic model and an efficient computational algorithm for performing phase stability and multiphase flash calculations.

The Peng-Robinson (PR) equation of state (EOS) was chosen for phase equilibria calculations. The PR EOS (with its several modifications) is one of the most popular equations for describing the PVT (Pressure-Volume-Temperature) behaviour of real pure substances and mixtures. This equation has the following classic form [2, 3]:

$$
p=\frac{R T}{v-b_{m}}-\frac{a_{m}}{v\left(v+b_{m}\right)+b_{m}\left(v-b_{m}\right)}
$$

Parameters $a_{m}$ and $b_{m}$ are defined from classic mixing rules:

$$
\begin{gathered}
a_{m}=\sum_{i} \sum_{j} z_{i} z_{j} a_{m_{i, j}} \\
b_{m}=\sum_{i} z_{i} \cdot b_{i}
\end{gathered}
$$

Other PR EOS parameters are defined as:

$$
\begin{gathered}
a_{m i, j}=\left(1-\delta_{i j}\right) \cdot \sqrt{a_{i} \alpha_{i} a_{j} \alpha_{j}} \\
\alpha_{i}=\left[1+m_{i}\left(1-\sqrt{\frac{T}{T_{c_{i}}}}\right)\right]^{2} \\
a_{i}=0.45724 \cdot \frac{R^{2} T_{c_{i}}^{2}}{p_{c_{i}}} \quad b_{i}=0.07780 \cdot \frac{R T_{c_{i}}}{p_{c_{i}}} \\
A=\frac{a_{m} p}{R^{2} T^{2}} \quad B=\frac{b_{m} p}{R T} \\
m_{i}=0.379642+1.48503 \omega_{i}-0.164423 \omega_{i}^{2}+0.016666 \omega_{i}^{3}
\end{gathered}
$$


PR equation of state with compressibility factor $Z$ is defined as:

$$
Z^{3}+(B-1) Z^{2}+\left(A-3 B^{2}-2 B\right) Z+\left(B^{3}+B^{2}-A B\right)=0
$$

Fugacity coefficient $\varphi_{i}$ may be calculated from the following formula:

$$
\ln \varphi_{i}=\frac{b_{i}}{b_{m}}(Z-1)-\ln (Z-B)-\frac{A}{2 \sqrt{2} B}\left(2 \cdot \frac{\sum_{j} z_{j} \cdot a_{m_{i, j}}}{a_{m}}-\frac{b_{i}}{b_{m}}\right) \cdot \ln \left(\frac{Z+(\sqrt{2}+1) B}{Z-(\sqrt{2}-1) B}\right)
$$

From the general form of real gas equation of state density can be written as:

$$
\rho=\frac{p}{Z R_{i} T}
$$

As a result of phase equilibria calculations for the analysed natural gas compositions phase envelopes plots (p-T plots) are presented in Figure 2. It is shown that two-phase system for natural gas composition I occurs in higher temperatures (impact of propane and butanes properties - higher conditions for critical point and higher bubble point temperature).

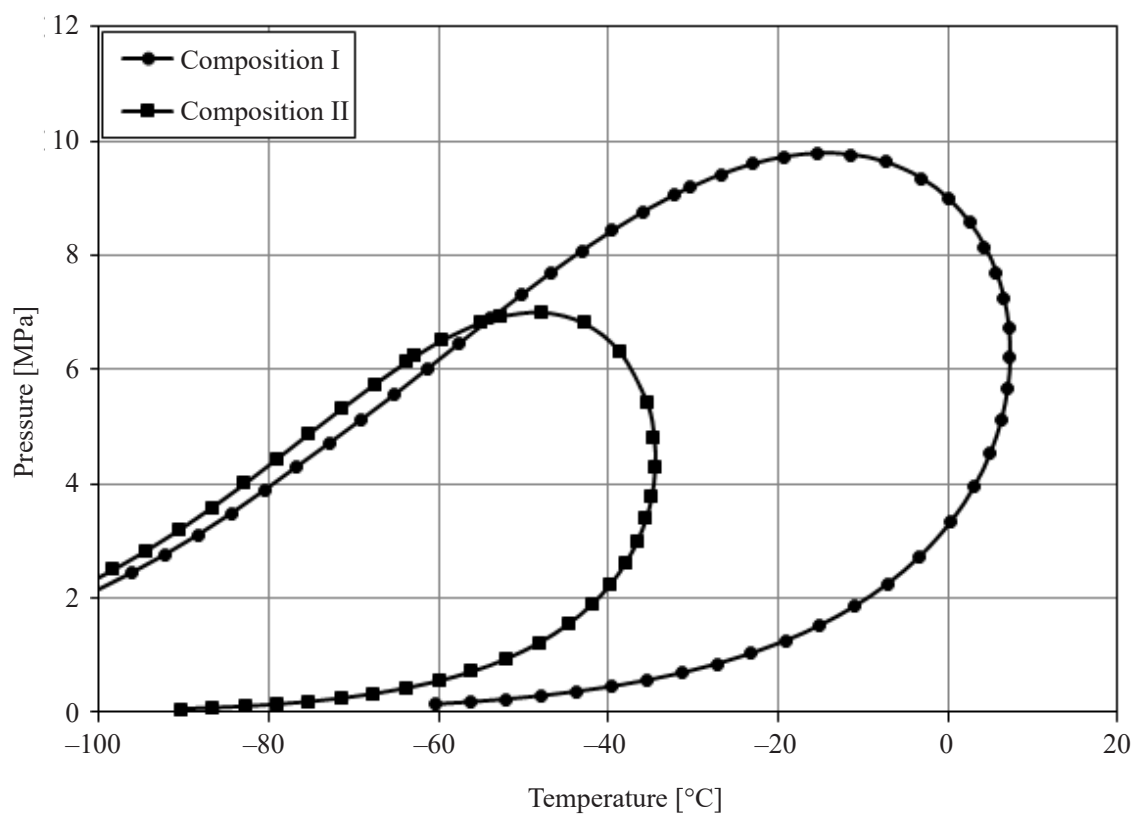

Fig. 2. Phase envelopes for analysed natural gas compositions 


\section{PIPELINE MODELING}

The Beggs and Brill correlation was adopted for liquid holdup and pressure gradient calculations in this paper. A brief, shortened summary of this method is presented below, as some of its equations and coefficients need to be referenced in subsequent discussions. Frictional pressure drop in this method is calculated from following formula $[4,5]$ :

$$
\left(\frac{d p}{d L}\right)_{f}=\frac{2 \cdot f_{t p} \cdot \rho_{n} \cdot w_{m}^{2}}{g \cdot D}
$$

where:

$$
\begin{aligned}
& \rho_{n}-\text { no-slip density: } \rho_{n}=\rho_{L} \frac{Q_{L}}{Q_{L}+Q_{V}}+\left(1-\frac{Q_{L}}{Q_{L}+Q_{V}}\right) \rho_{V}, \\
& f_{t p}-\text { two-phase friction factor: } f_{t p}=f_{n s} \cdot \exp (S), \\
& f_{n s}-\text { no-slip friction factor: } f_{n s}=\left[2 \cdot \log \left(\frac{\mathrm{Re}}{4.52 \cdot \log (\mathrm{Re})-3.8215}\right)\right]^{-2}, \\
& S-\text { correlation coefficient depending on two-phase flow pattern, } \\
& w_{m}-\text { mixture flow velocity. }
\end{aligned}
$$

The Beggs and Brill model also includes pressure drops from hydrostatic effects and kinetic energy impact, then the total pressure gradient is given by equation $[4,5]$ :

$$
\frac{d p}{d L}=\frac{\left(\frac{d p}{d L}\right)_{e l}+\left(\frac{d p}{d L}\right)_{f}}{1-E_{K}}
$$

The temperature changes model in a function of pipeline length is described with the formula [6-8]:

$$
T_{2}=T_{\text {out }}+\left(T_{1}-T_{\text {out }}\right) \exp \left(\frac{-L \cdot U \cdot \pi \cdot D}{\dot{M} \cdot C p}\right)+\frac{\dot{M}}{\pi \cdot U \cdot D}\left(\mu_{J T} \cdot C p \cdot \frac{d p}{d L}\right)\left(1-\exp \left(\frac{-L \cdot U \cdot \pi \cdot D}{\dot{M} \cdot C p}\right)\right)
$$

Joule-Thomson coefficient and isobaric heat capacity are calculated directly using and transforming PR EOS. The overall heat transfer coefficient for buried pipeline is described by equation $[8,9]$ :

$$
U=\frac{1}{\frac{r_{\text {out }}}{r_{\text {in }} \cdot \alpha_{\text {in }}}+\frac{r_{\text {out }} \cdot \ln \left(\frac{r_{\text {out }}}{r_{\text {in }}}\right)}{2 \pi k L}+\frac{1}{\alpha_{\text {out }}}}
$$




\section{RESULTS}

In this section the main results of the analysed pipeline model are presented. The obtained results include analysis of pressure and temperature changes as a function of the pipeline length. For determined conditions of pressure and temperature, an analysis of phase equilibria is presented. Equilibria calculations determine the phase in which natural gas flows for a given composition and $p, T$ conditions. Also as a result, the quantity of each phase and their compositions can be obtained. The calculation model also provides analysis of other related parameters changes such as density, viscosity and flow velocity as a function of the pipeline length.

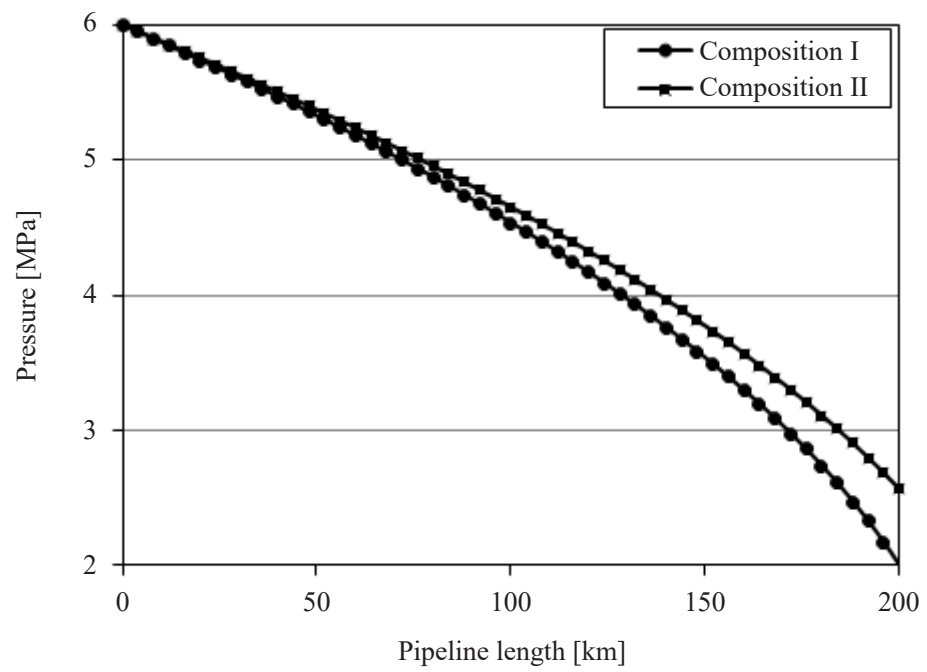

Fig. 3. Pressure changes as a function of pipeline length for analysed natural gas compositions

Pressure drops for selected pipeline parameters and two analysed natural gas compositions are shown in Figure 3. Analysis shows that pressure loss in the pipeline for composition I is higher, it is certain because this natural gas is heavier (higher molar mass). From the pressure changes diagram for composition I, it cannot be concluded that a two-phase system occurred. There is a completely different situation with temperature changes for this composition. In Figure 4 it is shown that the occurrence of a two-phase system is very probable for this natural gas. Temperature changes for composition II (high methane content dry gas) are normal for a typical natural gas high pressure pipeline. The transported natural gas with a higher initial temperature at some distance reached ambient temperature (ground temperature) and to the end point of the pipeline, the temperature is close to a constant value. In the case of composition I (wet gas, condensate gas), the temperature drop is more significant. Temperature drops more significantly to a distance of $165 \mathrm{~km}$ from pipeline inlet point. Then a temperature increase can be observed. Probably to a distance of $165 \mathrm{~km}$ the two-phase system occurs. To confirm this assumption, two plots are presented in Figure 5. The phase envelope for composition I is the first and pressure and temperature points as a function of pipeline length make up the second plot. 


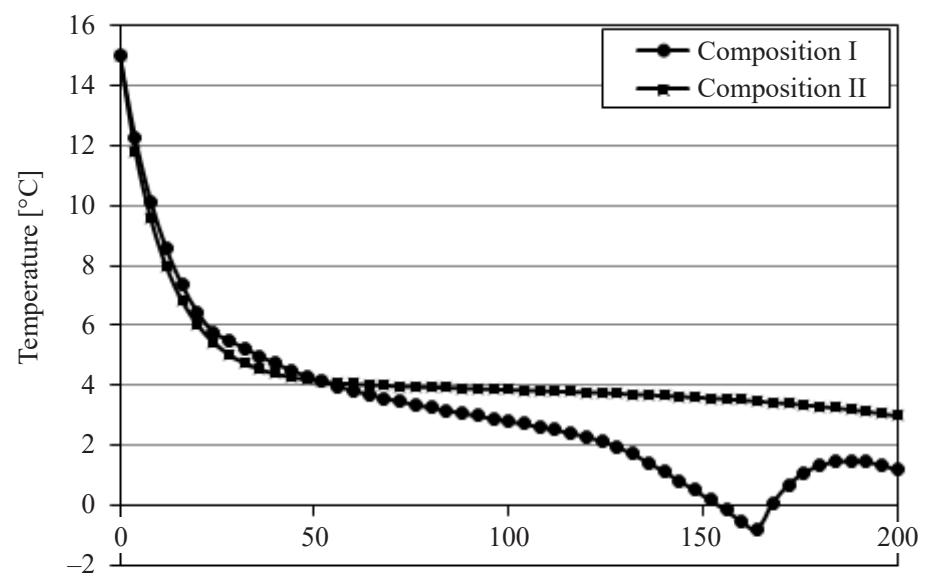

Pipeline length $[\mathrm{km}]$

Fig. 4. Temperature changes of analysed natural gases for presented pipeline

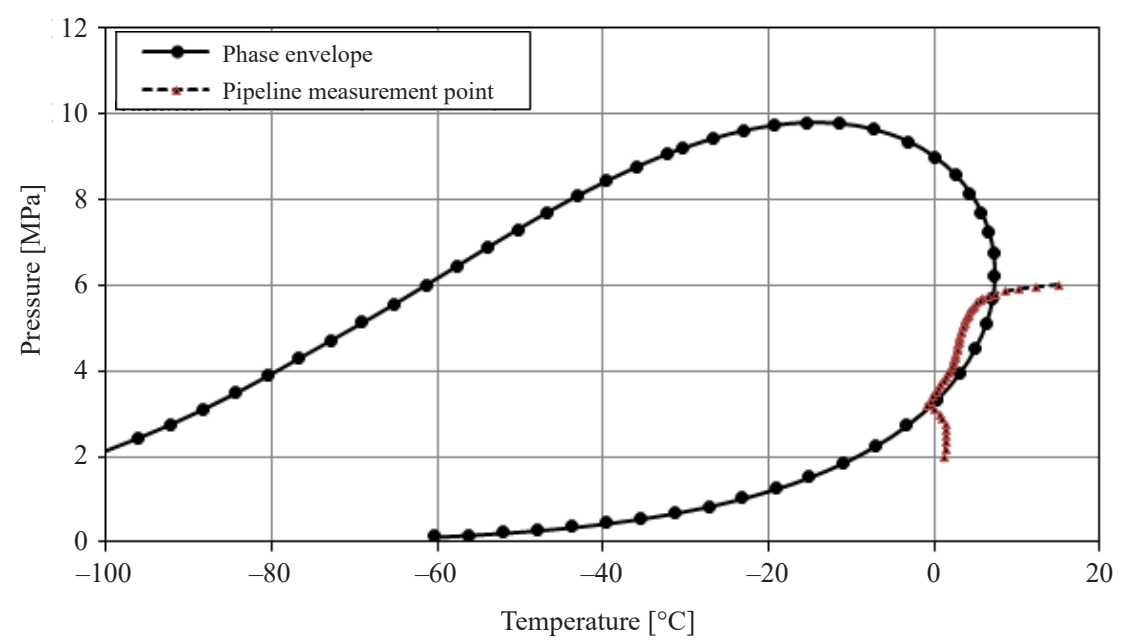

Fig. 5. Comparison of phase envelope and pressure and temperature conditions in pipeline for natural gas composition I

The analysis of the above graph confirms that for this case the two-phase system occurs in presented pipeline. A liquid phase appears in a stream of flowing natural gas and it causes a higher temperature drop and probably higher pressure losses in the pipeline but this phenomenon is not clearly visible. It indicates the low molar fraction of the liquid phase in a twophase system. The results of phase equilibria calculations confirmed these assumptions. In Figure 6, the molar fraction of the vapour phase as a function of pipeline length is presented. It can be observed that the liquid phase occurs from a distance of $24 \mathrm{~km}$ to $165 \mathrm{~km}$ from 
pipeline inlet point. The maximum liquid phase molar fraction is only $0.7 \%$ and maximum liquid mass flow rate is $681 \mathrm{~kg} / \mathrm{h}$ (Fig. 7). Also, density and viscosity change analysis were performed for the natural gases analysed. The obtained results are shown in Figures 8 and 9 respectively. Both the density and viscosity of the vapour phase significantly decreases with the pressure drop as a function of the pipeline length, but in the case of density decrease, it is more rapid after the complete evaporation of the condensate. The density and viscosity of liquid phase increase with the length of the pipeline until complete evaporation.

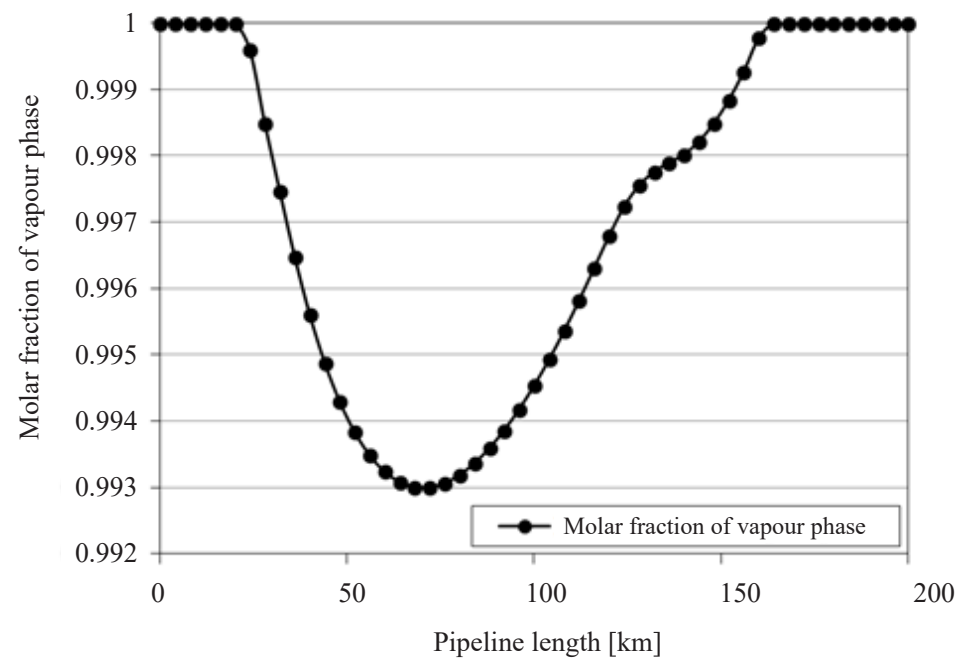

Fig. 6. Molar fraction of vapour phase versus pipeline length (Composition I)

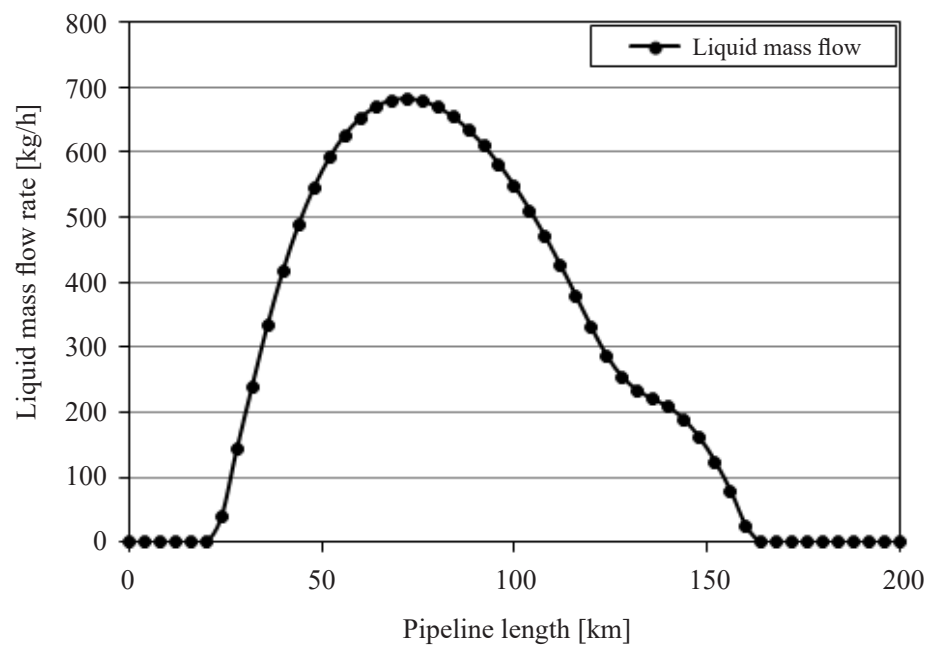

Fig. 7. Liquid mass flow rate as a function of pipeline length (Composition I) 


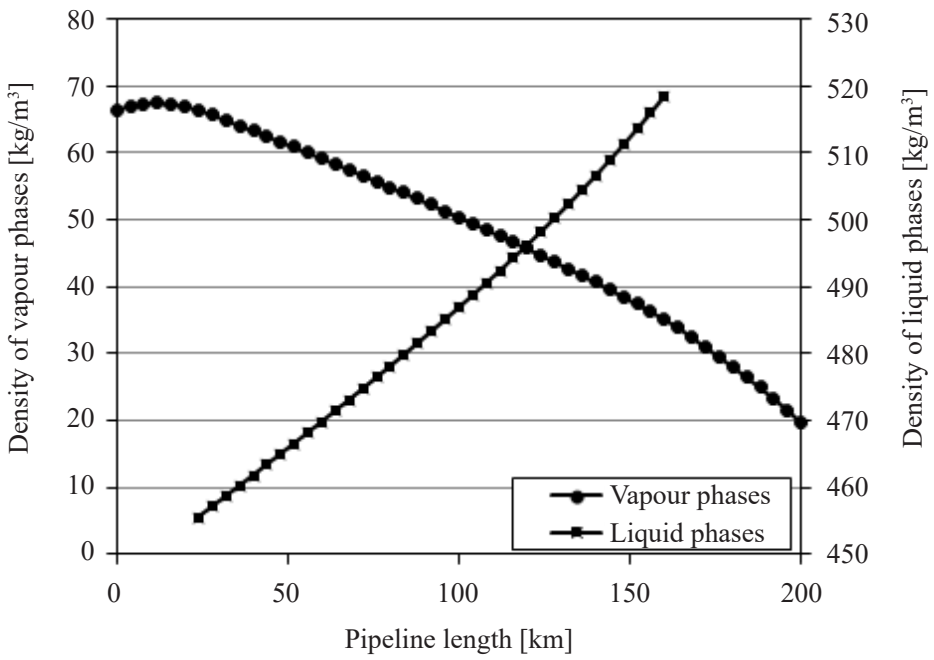

Fig. 8. Density changes of vapour and liquid phases for natural gas composition I

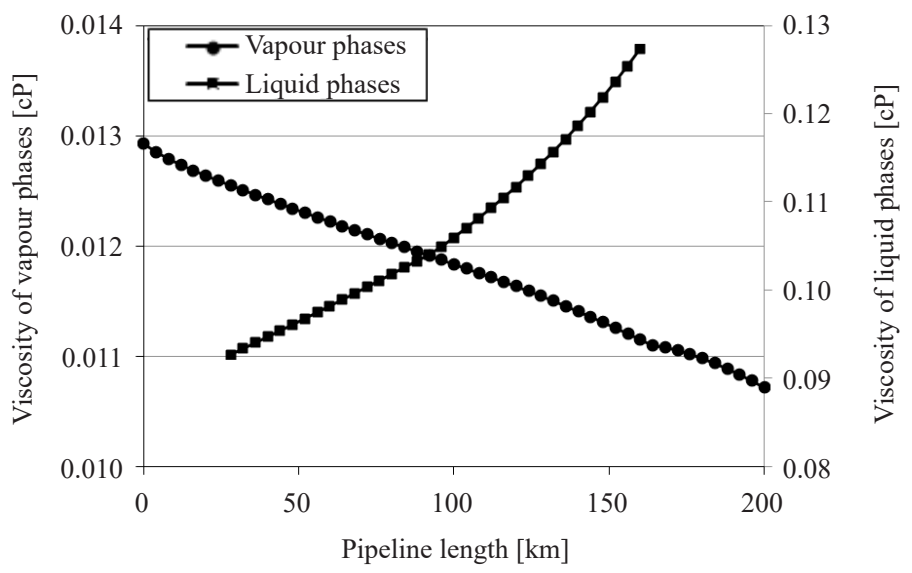

Fig. 9. Viscosity changes of vapour and liquid phases for natural gas composition I

Also, a composition analysis of the liquid was performed. and its results show that the main component of the liquid phase is methane (in the beginning of liquid occurrence, the molar fraction about $32 \%$ ), the second component is propane with $23 \%$ of molar fraction and the third is n-butane with $20 \%$ molar fraction (Fig. 10). It can be observed that the molar fraction of methane and ethane decreases while other content components (propane, butanes) increase with pressure and temperature changes along the pipeline. The main components of liquid phase before evaporation is n-butane $(28 \% \mathrm{~mol})$, propane $(25 \% \mathrm{~mol})$ and iso-butane $(20 \% \mathrm{~mol})$. The composition of the vapour phase practically does not change. When a liquid phase occurs in pipeline molar fraction of methane is slightly increased 
(up to $83.3 \%$ ) in the composition of the vapour phase. It can be observed also by slight decreasing of the molar mass of the vapour phase (Fig. 11). Fractions of other components decrease slightly. The molar mass of the liquid phase increases with the increase of butanes and propane content.

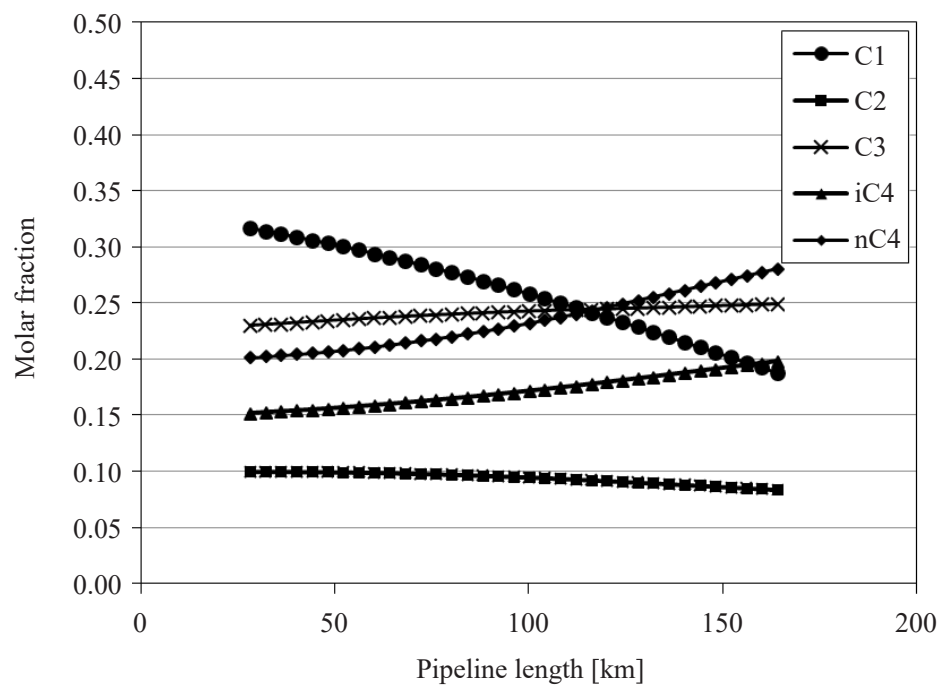

Fig. 10. Liquid phase components molar fraction as a function of pipeline length

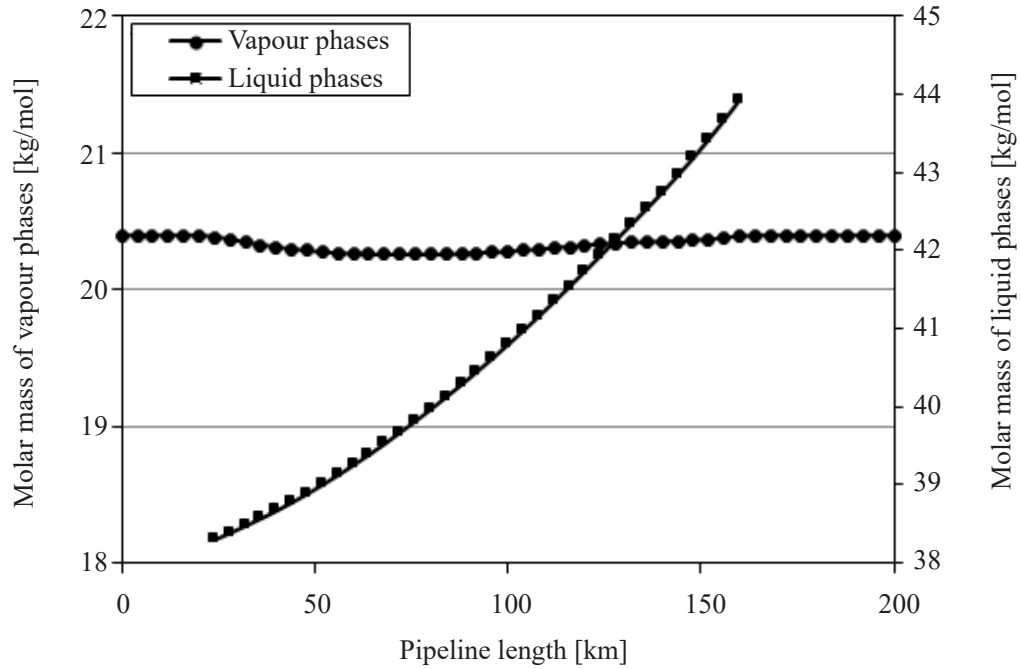

Fig. 11. Molar mass of vapour and liquid phases versus pipeline length 


\section{CONCLUSIONS}

The article presents an analysis of the possible occurrence of a two-phase system during the pipeline transportation of natural gas. The presented phenomenon is similar to retrograde condensation known from the exploitation of natural gas reservoirs. In the present case, a two phase-system occurs in the pipeline due to pressure drop and temperature changes. However, only the vapour phase at the pipeline inlet point and the outlet point were detected. The influence of the retrograde condensation effect on the variability of the basic parameters of the transported natural gas was indicated by the presented results. It should be noted that the probability of occurrence of condensation phenomenon is increased with the increase of the heavier hydrocarbon molar fraction in the natural gas composition. It is confirmed that this phenomenon does not occur for dry gas at typical pressure and temperature conditions in pipeline. The paper presents the results of phase equilibria calculations which indicated that although there are higher contents of heavier hydrocarbons in natural gas composition, the amount of condensed liquid phase is very low. The availability of a calculation models that accurately predicts the amount of the liquid phase formed in the pipeline is of great importance for the natural gas pipeline operators. The objective of this study was to develop a calculation model for the prediction of the amount of the liquid phase formed in natural gas pipelines under transportation conditions.

\section{NOMENCLATURE}

$a, b$ - Peng-Robinson EOS parameters,

$A, B$ - dimensionless Peng Robinson EOS parameters,

$C_{p} \quad-$ mass isobaric heat capacity $[\mathrm{J} /(\mathrm{kg} \cdot \mathrm{K})]$,

$D$ - diameter of pipeline [m],

$f_{i} \quad$ - fugacity $[\mathrm{Pa}]$,

$f_{t p} \quad-$ two-phase friction factor $[-]$,

$k-$ thermal conductivity $[\mathrm{W} /(\mathrm{m} \cdot \mathrm{K})]$,

$L$. - pipeline length [m],

$\dot{M} \quad$ - mass flow rate $[\mathrm{kg} / \mathrm{s}]$,

$p \quad$ - pressure $[\mathrm{Pa}]$,

$p_{c} \quad$ - critical pressure $[\mathrm{Pa}]$,

$p^{\text {sat }}$ - saturation pressure $[\mathrm{Pa}]$,

$Q \quad$ - volume flow rate $\left[\mathrm{m}^{3} / \mathrm{s}\right]$,

$R$ - radius of pipeline [m],

$R_{i} \quad$ - individual gas constant $[\mathrm{J} /(\mathrm{kg} \cdot \mathrm{K})]$,

$T$ - temperature $[\mathrm{K}]$,

$T_{c} \quad$ - critical temperature $[\mathrm{K}]$,

$U$ - overall heat transfer coefficient $\left[\mathrm{W} /\left(\mathrm{m}^{2} \cdot \mathrm{K}\right)\right]$,

$w_{m} \quad$ - flow velocity of mixture $[\mathrm{m} / \mathrm{s}]$,

$x_{i}-i$ component molar fraction in liquid phase [-],

$y_{i}-i$ component molar fraction in liquid phase $[-]$,

$z_{i} \quad-i$ component molar fraction $[-]$, 
Z - compressibility factor [-],

$\alpha, m \quad$ - Peng-Robinson EOS parameters,

$\alpha_{\text {in }}, \alpha_{\text {out }}-$ convective heat transfer coefficient $\left[\mathrm{W} /\left(\mathrm{m}^{2} \cdot \mathrm{K}\right)\right]$,

$\delta_{\mathrm{ij}} \quad$ - binary interaction coefficient,

$\mu_{\mathrm{JT}} \quad-$ Joule-Thomson coefficient $[\mathrm{K} / \mathrm{Pa}]$,

$\rho-$ density $\left[\mathrm{kg} / \mathrm{m}^{3}\right]$,

$\phi_{i} \quad$ - fugacity coefficient of $i$ component [-],

$\omega-$ acentric factor $[-]$.

\section{REFERENCES}

[1] Voulgaris M.E., Peters C.J., Swan Arons J. de: On the retrograde condensation behavior of lean natural gas. International Journal of Thermophysics, vol. 16, iss. 3, 1995, pp. 629-642.

[2] Nagy S.: Termodynamiczne podstawy gazownictwa. In: Vademecum gazownika. T. 1: Podstawy gazownictwa ziemnego: pozyskiwanie, przygotowanie do transportu, magazynowanie, red. S. Nagy. SITPNiG, Kraków 2014.

[3] Peng D.Y., Robinson D.B.: A New Two-Constant Equation of State. Industrial and Engineering Chemistry Fundamentals, vol. 15, no. 1, 1976, pp. 59-64.

[4] Beggs H.D., Brill J.P.: A Study of Two-Phase Flow in Inclined Pipes. Journal of Petroleum Technology, vol. 25, no. 5, 1973, pp. 607-617.

[5] Brill J.P., Beggs H.D.: Two-Phase Flow in Pipes. 5th Edition, University of Tulsa, Tulsa, Oklahoma 1986.

[6] Duan J., Wang W., Zhang Yu., Liu H., Lin B., Gong J.: Calculation of inner wall temperature in oil-gas pipe flow. Journal of Central South University, vol. 19, iss. 7, 2012, pp. 1932-1937.

[7] Abdolahi Farzad et al.: The effect of major parameters on simulation results of gas pipelines. International Journal of Mechanical Sciences, vol. 49, 2007, pp. 989-1000.

[8] Shashi Menon E.: Gas pipeline hydraulics. CRC PRESS, 2005.

[9] Bai Y., Bai Q.: Subsea Pipelines and Risers. Elsevier, 2005. 